\section{No lack of individuality}

Sir - Audrey Wells writes that "Confucianinfluenced cultures such as China, Korea, Japan and Vietnam were not deeply permeated by Christianity and its concomitant emphasis on the importance of the individual" (Nature 386, 14; 1997). We contend that if lack of individuality is indeed the case, original Confucianism had nothing to do with it. The original Rú Jiā philosophers placed emphasis on individuality and self-examination. In Lùn $Y \breve{u}$ (Analects), we have : "the Master said, 'When the multitude hate a man, it is necessary to examine the case. When the multitude like a man, it is necessary to examine the case."' (James Legge's translation for this and other quotations.) Mencius continued in this tradition, and Mēng Ž̌ has this passage: "I heard an account of great valour from the Master. It speaks thus, 'If, on self-examination, I find that I am not upright, shall I not be in fear even of a poor man in his loose garment of haircloth? If, on self-examination, I find that I am upright, I will go forward against thousands and tens of thousands." "This is a philosophy that encourages the individual to think and act independently.

Authoritarianism is also a trait unknown in the original writings of the Confucian philosophers. What they respected was not power or authority, but virtue. Mēng $Z \grave{i}$ has the following: "Respect shown by inferiors to superiors is called giving to the noble the observance due to rank. Respect shown by superiors to inferiors is called giving honour to talents and virtue. The rightness in each case is the same." And deference towards seniors is only half the story; there is also deference towards the young. In Lùn Yü, Confucius was recorded as having said, "A youth is to be regarded with respect. How do we know that his future will not be equal to our present?"

Before Galileo, Chinese science was much more advanced than science in Christendom - or anywhere else for that matter. The most authoritative scholar on the relationship between Chinese science and Taoism is probably the late Joseph
Needham. In his Science and Civilization in China (Cambridge University Press), he wrote that Taoism was the main driving force behind Chinese science, because of the Taoist view on the harmony between Man and Nature. He never associated Taoism with paradoxes, and it would be interesting to know how they are related to Taoism, because, to our knowledge, paradoxes have never been connected to Taoism.

Nevertheless, Needham also mentioned that Confucianism contributed to scientific developments as well, albeit to a lesser extent, by providing the necessary social infrastructure. In his magnum opus, one can examine these developments. It is clear that the ancient Chinese, at least up to the time of the Scientific Revolution, did not lack individuality or independence of spirit, two qualities (among many others) conducive to scientific development. We would further suggest that the Confucian ideals of self-examination and moral courage probably contributed to this individuality and independence of spirit. Needham also explored the possible reasons against a scientific revolution in China, and it appears to be less simple than just the lack of Christian-influenced individualism.

Lastly, Audrey Wells contends that "Confucianism does encourage selfdiscipline". May we ask what philosophy or religion does not encourage self-discipline? Do Buddha, Socrates and Plato, or the Bible, the Koran and the Vedas not do the same? And is it statistically significant to generalize from Western musical education in Korea and Japan in the past 30 years or so to arrive at a general conclusion about a complex 2,500-year-old philosophy that has deeply influenced the whole of East Asia?

\section{P.-L. Chau}

Kemisk Laboratorium III,

H.C. Ørsted Institutet,

Københavns Universitet,

DK-2100 København $\emptyset$, Denmark

e-mail:chau@st.ki.ku.dk

W. Y. Chau

30/74 Wardell Road,

Sydney 2206, Australia

annotated sequence of almost all the $E$. coli genome determined by us has been in the public database. Our data, like those of Blattner et al., are of the highest quality, and our analysis of sequence features has been even further extended.

Takashi Horiuchi

National Institute for Basic Biology,

38 Nishigonaka, Myodaijicho,

Okazaki 444, Japan

e-mail:kishori@nibb.ac.jp
Contract researchers still out in the cold

Sir - A recent leading article (Nature 386, 201; 1997) stated: "The Natural Environment Research Council [NERC]'s enlightened policy is that any employee of more than five years' standing should be permanent. Unfortunately, many such employees are still impermanent."

While it is correct that many NERC employees with more than five years' continuous service are still on fixed-term contracts (and are thus impermanent), your statement does not correctly summarize NERC's policy. This policy is that (in theory) staff on fixed-term appointments approaching five years' service will be reviewed, and, at the end of the contract, either will be offered an open-ended post or their position will be terminated. However, as the governing council of NERC insisted that the policy be implemented at a local level within NERC's institutes, the policy is being interpreted very differently in different parts of NERC. At the British Antarctic Survey for example, the stated policy is that only researchers who are "high flyers" of "outstanding/ excellent ability" will be retained. This description is usually reserved for staff given a "box 1 " mark on their annual personal review approximately $5-10 \%$ of the staff — which doesn't make the policy particularly attractive for the remaining $90 \%$ on fixed-term contracts.

The NERC policy may, in principle, seem enlightened, but it is the practice of this policy that matters. Directors within NERC are still more concerned to "maintain flexibility" by increasing the numbers of staff on fixed-term appointments than in creating an environment and career structure within which scientists can flourish over the longer term. As your leading article concludes: "Every means should be found to keep up the pressure on all employers who keep contract researchers... in a state of unjust personal disadvantage." The trade unions within NERC, led by the Institution of Professionals, Managers and Specialists (IPMS) representing the scientists, continue to campaign for better terms and condition for those on fixed-term contracts, and it looks as if we will be campaigning for some time to come.

\section{Tina Yates}

(President, NERC Branch IPMS)

Institute of Terrestrial Ecology,

Monks Wood, Abbots Ripton,

Huntingdon, Cambs PE18 9LE, UK

In fact, since 24 January 1997, the 